\title{
Bohra nullarbora sp. nov., a second tree-kangaroo (Marsupialia: Macropodidae) from the Pleistocene of the Nullarbor Plain, Western Australia
}

\author{
Gavin J. Prideaux ${ }^{1,3}$ and Natalie Warburton ${ }^{2,3}$ \\ ${ }^{1}$ School of Biological Sciences, Flinders University, Bedford Park, South Australia 5042, Australia. \\ E-mail: gavin.prideaux@flinders.edu.au \\ ${ }^{2}$ School of Veterinary \& Biomedical Sciences, Murdoch University, Murdoch, Western Australia 6150, Australia. \\ E-mail: n.warburton@murdoch.edu.au \\ ${ }^{3}$ Department of Earth and Planetary Sciences, Western Australian Museum, Welshpool, \\ Western Australia 6106, Australia.
}

\begin{abstract}
Bohra nullarbora sp. nov. is described from a partial skeleton collected from a diverse Pleistocene vertebrate assemblage preserved in Leaena's Breath Cave, Nullarbor Plain, Western Australia. It is distinguished from its Nullarbor contemporary, B. illuminata, by having different cranial proportions, smaller cheek teeth and a relatively narrower upper premolar. It also differs in a number of postcranial attributes, which may reflect slight variation in locomotory capabilities. The unexpected discovery that, in the relatively recent geological past, two large arboreal kangaroos inhabited the now 'Treeless' Plain effectively highlights how little we still know about the Pleistocene history of Western Australia, and of the drier regions of the continent in general.
\end{abstract}

\section{INTRODUCTION}

Extant tree-kangaroos (Dendrolagus) inhabit the forests of far northeastern Queensland and New Guinea (Flannery 1990; Strahan 1995). Their ancestors appear to have evolved from terrestrial kangaroos some time in the latter part of the Miocene (Flannery 1989). Tree-kangaroos are rarely preserved, or at least have been rarely recognised, as fossils. Flannery and Szalay (1982) described a large new genus and species of tree-kangaroo (Bohra paulae) from the Wellington Caves in central eastern New South Wales (Figure 1) on the basis of some hind limb elements. Craniodental material from the Pliocene of Chinchilla in Queensland was referred to the same genus by Dawson (2004), a decision later supported when the first of the new species, B. illuminata, was described by Prideaux and Warburton (2008) from Pleistocene deposits in the Thylacoleo Caves, Nullarbor Plain, Western Australia (Prideaux et al. 2007; Figure 1). The holotype of B. illuminata consists of much of one skeleton, including the complete cranium. Hocknull $(2005 a, b)$ recorded remains referable to the genera Bohra and Dendrolagus from the Mt Etna cave-fills (near Rockhampton in Queensland) of middle Pleistocene age (Hocknull et al. 2007). Undescribed Pleistocene tree-kangaroo elements are also known from Curramulka Quarry,
Yorke Peninsula, South Australia, and the eastern Darling Downs (pers. obs.; Figure 1).

This paper describes the holotype and only known specimen of Bohra nullarbora sp. nov., a partial skeleton from Leaena's Breath Cave, one of the three caves near the centre of the Nullarbor Plain known collectively as the Thylacoleo Caves (Figure 1). The caves contain well-preserved skeletal remains of a diverse middle Pleistocene vertebrate fauna (Prideaux et al. 2007), including eight kangaroo species entirely new to science. An overview of the significance of the sites and likely palaeoenvironment was provided by Prideaux et al. (2007). Analyses of the functional morphology of the forelimb and hind limb, which confirm the arboreal aptitude of the Nullarbor species of Bohra, are presented in Harvey (2006) and Warburton and Prideaux (in press), respectively. Refer to Prideaux and Warburton (2008) for a more detailed comparison of Bohra and Dendrolagus.

The holotype of $B$. nullarbora is registered in the vertebrate palaeontological collections of the Western Australian Museum, Perth (abbreviation WAM). Description style, terminology and mensuration follow Prideaux (2004) for the craniodental system, and Owen (1876), Murray (1995), Wells and Tedford (1995), the Nomina 
Anatomica Veterinaria (2005), Weisbecker and Sánchez-Villagra (2006) and Prideaux and Warburton (2008) for the postcranial skeleton. Serial designation of the cheek dentition follows Flower (1867) and Luckett (1993). Upper teeth are designated by upper case abbreviations (e.g. P3, M2); lower teeth are designated by lower case abbreviations (e.g. i1, m3).

\section{SYSTEMATIC PALAEONTOLOGY}

Diprotodontia Owen, 1866

Superfamily Macropodoidea (Gray, 1821)

Family Macropodidae Gray, 1821

Subfamily Macropodinae Gray, 1821

Tribe Dendrolagini Flannery, 1989

Genus Bohra Flannery \& Szalay, 1982

\section{Type species}

Bohra paulae Flannery and Szalay, 1982.

Bohra nullarbora sp. nov.

Figures 2-6, Tables 1-3

\section{Material examined}

\section{Holotype}

Australia: Western Australia: WAM 05.4.70, partial adult cranium, partial left and right dentaries; vertebrae (atlas, axis, cervical 3-5, thoracic 1, ?5-6, ?10, ?12, dorsal lumbar fragment, two mid-caudal and two distal-caudal vertebrae, 1 mid-caudal chevron), left and right clavicles, six ribs, humerus (left proximal and distal fragments, right partial diaphysis), left ulna, left radius (diaphysial fragment), carpals (right hamatum, left scaphoid), metacarpals (left and right III, left IV-V), manual phalanges (digits I-IV proximal; digits III-V medial; digits III-IV distal), innominates (partial left; fragments of right), left epipubic, femur (proximal portion of left, abraded distal fragments of right), tibia (right diaphysis, left distal diaphysis fragments), fibula (distal portion), left calcaneus, talus and navicular, right entocuneiform, metatarsals IV-V, pedal phalanges (digit II, IV-V proximal, digit II-V medial; digits IV-V distal) (Figure 1; Tables 1-2).

\section{Type locality and age}

The holotype was collected by P. D. Devine and G. J. Prideaux in July 2002 from the floor of Leaena's Breath Cave, Nullarbor Plain, southeastern Western Australia (Figure 1). Precise location and

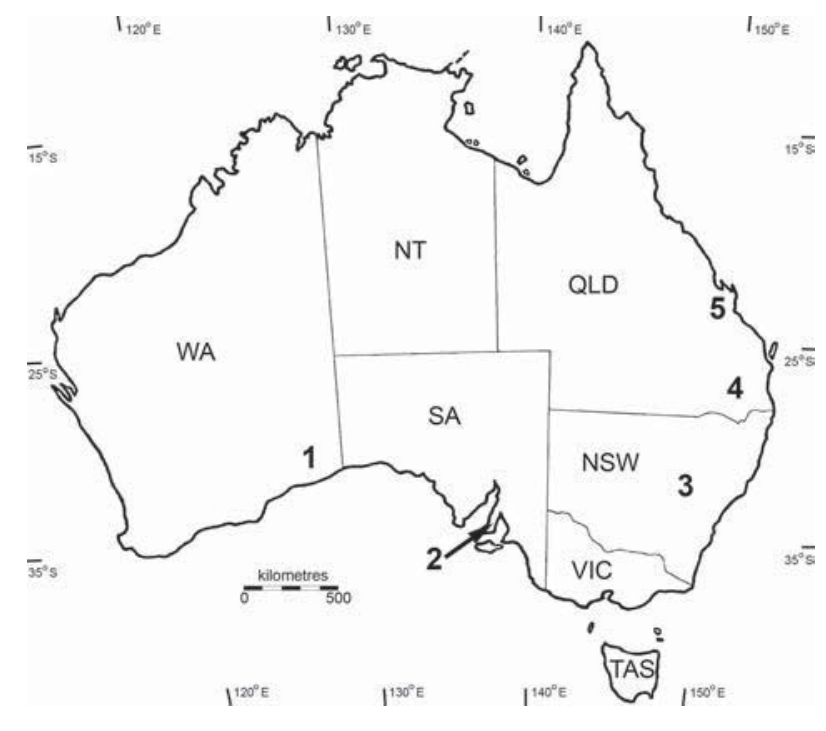

Figure 1 Map showing Australian localities yielding Pleistocene tree-kangaroos. 1, Thylacoleo Caves, middle Pleistocene, Bohra illuminata and $B$. nullarbora; 2, Curramulka Quarry, ?Pleistocene, Bohra sp. indet. (pers. obs.); 3, Wellington Caves, ?Pleistocene, Bohra paulae (Flannery and Szalay, 1982); 4, eastern Darling Downs, Bohra sp. indet. (pers. obs.); 5, Mt Etna cave-fills, Bohra sp. indet., Dendrolagus sp. indet., middle Pleistocene (Hocknull 2005a,b; Hocknull et al. 2007).

site details are registered with the Department of Earth and Planetary Sciences, Western Australian Museum, Perth. Fossils from the cave-floor and upper sediment unit of Leaena's Breath Cave are probably early middle Pleistocene in age (Prideaux et al. 2007).

\section{Diagnosis}

Distinguished from Bohra paulae by having smaller calcaneus with tuber calcanei less barrelshaped, partial separation of posterior calcanealtalar facets, longer sustentaculum, shorter plantar sulcus, calcaneal-cuboid facets flat rather than V-shaped in transverse plane, smaller, relatively longer talus, narrower trochlea, higher lateral trochlear crest of talus.

Distinguished from Bohra wilkinsonorum by having distinctly smaller cheek teeth and by lacking posterobuccal accessory cusp, thin low buccal cingulum and thick lingual cingulum on P3, and distinct lingual 'hook' of postparacrista on upper molars.

Distinguished from Bohra illuminata on the basis of the following craniodental attributes. Incisorbearing portion of premaxilla deep; buccinator fossa shallow; narial aperture near-circular; 
Table 1 Dimensions (in $\mathrm{mm}$ ) of the cranium and dentary of the holotype of Bohra nullarbora sp. nov. (WAM 05.4.70) compared with those of B. illuminata (WAM 03.5.10).

\begin{tabular}{lll}
\hline Dimension & B. nullarbora & B. illuminata \\
\hline Width across zygomatic arches & 79.5 & 75.2 \\
Width across frontals & ca 29.7 & 23.8 \\
Distance between masseteric processes & ca 49.4 & 48.1 \\
Palatal width at M1 protoloph & 20.9 & 18.6 \\
Palatal width at M4 protoloph & 23.4 & 17.8 \\
Dentary depth at m2-3 & 18.3 & 14.4 \\
Dentary width at m2-3 & 8.23 & 7.83 \\
\hline
\end{tabular}

masseteric process tiny; supraorbital crest distinct, positioned above posterior portion of orbit, with distinct sulcus beneath; zygomatic arch moderately deep; ectoglenoid process rather wide; postglenoid process ventrally projected. Cheek teeth smaller relative to size of cranium; P3 wider anteriorly than posteriorly, bearing small, low posterolingual cusp and narrow lingual cingulum; buccal enamel on i1 forms quite thick dorsal flange, posterior end of ventral enamel flange very thin; lower molars bear low paracristid and premetacristid, with latter extending to centre of trigonid basin, small precingulid, and very low cristid obliqua.

Distinguished from Bohra illuminata on the basis of the following postcranial attributes. Clavicle more robust and less flattened, with expanded articular facets and more laterally positioned anterior inflection. Humerus more robust with stronger pectoral crest, deltoid ridge, bicipital groove and spino-deltoid insertion, but

Table 2 Cheek tooth dimensions (in $\mathrm{mm}$ ) of the holotype of Bohra nullarbora sp. nov. (WAM 05.4.70) compared with those of B. illuminata (WAM 03.5.10). Abbreviations: $\mathrm{L}=$ length, $\mathrm{AW}=$ anterior width, $\mathrm{PW}=$ posterior width, $\mathrm{AH}=$ anterior height, $\mathrm{PH}=$ posterior height.

\begin{tabular}{|c|c|c|c|c|c|c|}
\hline Species & Tooth & $\mathbf{L}$ & AW & PW & $\mathbf{A H}$ & PH \\
\hline \multirow[t]{5}{*}{ B. nullarbora } & P3 & 8.93 & 4.42 & 4.14 & 4.23 & 3.61 \\
\hline & M1 & 7.39 & 6.44 & 6.92 & - & - \\
\hline & M2 & 8.38 & 7.39 & 7.07 & - & - \\
\hline & M3 & 8.64 & 7.94 & 6.62 & 3.74 & 3.68 \\
\hline & M4 & 8.57 & 7.14 & 5.67 & 3.86 & 4.17 \\
\hline \multirow[t]{5}{*}{ B. illuminata } & P3 & 9.40 & 4.02 & 5.24 & 5.69 & 5.27 \\
\hline & M1 & 7.17 & 6.99 & 6.69 & - & - \\
\hline & M2 & 8.82 & 7.50 & 6.93 & 4.05 & 4.65 \\
\hline & M3 & 9.41 & 7.81 & 7.04 & 4.40 & 4.74 \\
\hline & M4 & 10.00 & 7.65 & 6.49 & 4.68 & 5.25 \\
\hline \multirow[t]{5}{*}{ B. nullarbora } & p3 & - & - & - & - & - \\
\hline & $\mathrm{m} 1$ & 6.94 & 4.57 & 4.58 & - & - \\
\hline & $\mathrm{m} 2$ & 7.90 & 5.44 & 5.47 & - & - \\
\hline & $\mathrm{m} 3$ & 9.12 & 6.03 & 6.08 & 3.65 & 4.32 \\
\hline & $\mathrm{m} 4$ & 8.51 & 6.04 & 5.47 & 3.76 & - \\
\hline \multirow[t]{4}{*}{ B. illuminata } & p3 & - & - & - & - & - \\
\hline & $\mathrm{m} 1$ & - & 4.61 & 5.14 & - & - \\
\hline & $\mathrm{m} 2$ & 8.34 & 5.58 & 5.71 & 3.67 & 4.61 \\
\hline & $\mathrm{m} 3$ & 10.65 & 6.56 & 6.81 & 5.30 & 5.87 \\
\hline
\end{tabular}


Table 3 Dimensions (in mm) of postcranial elements of the holotype of Bohra nullarbora sp. nov. (WAM 05.4.70) compared with those of B. illuminata (WAM 03.5.10) and B. paulae (AM F62099-F62101). Abbreviations: C, cervical; est., estimated; H, height; L, length; $\mathrm{W}$, width; $\mathrm{T}$, thoracic.

\begin{tabular}{|c|c|c|c|}
\hline Element & $\begin{array}{c}\text { Bohra } \\
\text { nullarbora }\end{array}$ & $\begin{array}{c}\text { Bohra } \\
\text { illuminata }\end{array}$ & Bohra paulae \\
\hline \multicolumn{4}{|l|}{ VERTEBRAE } \\
\hline C1 (width across postzygapophyses) & 50.6 & 25.8 & \\
\hline C2 (centrum dimensions) & $9.2 \times 6.8$ & & \\
\hline C2 (height including spine) & 29 & & \\
\hline C2 (Ventral length including odontoid process) & 23.4 & & \\
\hline C 3,4 (posterior centrum width) & $8.9,9.3$ & & \\
\hline C3,4 (centra length) & $13.8,12.5$ & & \\
\hline T1 (anterior centra dimensions) & $9.6 \times 6.3$ & $8.1 \times 5.7$ & \\
\hline T1 (centrum length) & 10.7 & 10.6 & \\
\hline T?5,6 (centra length) & $12.7,12.8$ & & \\
\hline T?10 (centrum length) & 13.8 & & \\
\hline Mid-caudals (centra length) & $45.8,47.2$ & & \\
\hline Distal caudal (centrum length) & 34.8 & & \\
\hline \multicolumn{4}{|l|}{ CLAVICLE } \\
\hline Length & 49.5 & 42.4 & \\
\hline \multicolumn{4}{|l|}{ HUMERUS } \\
\hline Maximum length (est.) & 110 & 105 & \\
\hline Maximum distal width & 39 & 37.4 & \\
\hline Width distal articular surface & 21.8 & 25.5 & \\
\hline \multicolumn{4}{|l|}{ RADIUS } \\
\hline Dimensions mid-shaft (HxW) & $9.2 \times 7.2$ & & \\
\hline \multicolumn{4}{|l|}{ ULNA } \\
\hline Maximum length (est.) & 150 & 140 & \\
\hline Anteroposterior length at coronoid fossa & 13.5 & 13.4 & \\
\hline Transverse width at coronoid fossa & 8.7 & 9.0 & \\
\hline \multicolumn{4}{|l|}{ METACARPALS } \\
\hline Metacarpal III length (left, right) & $28.4,28.1$ & 22.9 & \\
\hline Metacarpal IV length & 25.3 & 18.8 & \\
\hline Metacarpal V length & 20.3 & 15.7 & \\
\hline \multicolumn{4}{|l|}{ CARPALS } \\
\hline Hamatum maximum length & 10.5 & 12.4 & \\
\hline Hamatum maximum width & 14.5 & 7.8 & \\
\hline Hamatum maximum height & 11.3 & 8.6 & \\
\hline Scaphoid maximum length & 9.1 & & \\
\hline Scaphoid maximum width & 18 & & \\
\hline Scaphoid maximum height & 6.3 & & \\
\hline \multicolumn{4}{|l|}{ INNOMINATE } \\
\hline Sacroiliac articular surface width & 26.3 & & \\
\hline Acetabular fossa (LxW) & $23.5 \times 23.4$ & $21.8 \times 24.2$ & \\
\hline \multicolumn{4}{|l|}{ EPIPUBIC } \\
\hline Maximum length & 78.2 & 62 & \\
\hline Articular surface $(\mathrm{LxW})$ & $11.7 \times 6.3$ & $-x 16.6$ & \\
\hline \multicolumn{4}{|l|}{ FEMUR } \\
\hline Maximum diaphysis length & 150 & & \\
\hline
\end{tabular}


Table 3 (continued)

\begin{tabular}{|c|c|c|c|}
\hline Element & $\begin{array}{c}\text { Bohra } \\
\text { nullarbora }\end{array}$ & $\begin{array}{c}\text { Bohra } \\
\text { illuminata }\end{array}$ & Bohra paulae \\
\hline Articular head (LxW) & $23.0 \times 21.5$ & & \\
\hline Mid-shaft dimensions $(\mathrm{HxW})$ & $17.4 \times 18.8$ & & \\
\hline \multicolumn{4}{|l|}{ TIBIA } \\
\hline Maximum diaphysis length (est.) & 175 & 183 & \\
\hline \multicolumn{4}{|l|}{ FIBULA } \\
\hline \multicolumn{4}{|l|}{ Proximal epiphysis } \\
\hline \multicolumn{4}{|l|}{ CALCANEUS } \\
\hline Maximum length & 43.4 & 36.1 & \\
\hline Maximum width & 27.7 & 23.7 & \\
\hline Depth tuber calcanei & 16.5 & 13.7 & \\
\hline Talar articulation width & 22 & 19.9 & \\
\hline Dorsomedial facet width & 10.9 & 10.0 & \\
\hline Dorsolateral facet width & 6.8 & 6.2 & \\
\hline Width ventromedian facet & 8.4 & 8.2 & \\
\hline \multicolumn{4}{|l|}{ TALUS } \\
\hline Maximum length & 24.2 & 21.0 & \\
\hline Maximum width & 28.7 & 26.1 & \\
\hline Transverse distance between trochleas & 15.2 & 14.3 & \\
\hline Navicular facet (head) & $11.0 \times 9.7$ & $10.6 \times 9.1$ & \\
\hline \multicolumn{4}{|l|}{ NAVICULAR } \\
\hline Maximum height & 13.3 & & \\
\hline Length of dorsal surface & 16.1 & & \\
\hline Dorsal transverse width & 9.6 & & \\
\hline \multicolumn{4}{|l|}{ METATARSAL IV } \\
\hline Diaphysis length & 68.6 & & \\
\hline Proximal transverse width & 16.2 & & \\
\hline Distal transverse width (epiphysis) & 14.9 & & \\
\hline Metatarsal V facet & $10.4 \times 5.1$ & & \\
\hline Sesamoid facet & $7.0 \times 5.0$ & & \\
\hline \multicolumn{4}{|l|}{ METATARSAL V } \\
\hline Maximum shaft length & 60.1 & & \\
\hline Proximal transverse width & 13.9 & & \\
\hline Distal transverse width & 11.6 & & \\
\hline \multicolumn{4}{|l|}{ PHALANGES } \\
\hline Proximal phalanx IV length & 33.6 & & \\
\hline Proximal phalanx IV mid-width & 10.7 & & \\
\hline Medial phalanx IV length & 23.6 & & \\
\hline Medial phalanx IV mid-width & 9.5 & & \\
\hline Distal phalanx IV length & 29.4 & & \\
\hline Distal phalanx IV mid-width & 10.5 & & \\
\hline Proximal phalanx V length & 24.1 & & \\
\hline Proximal phalanx V mid-width & 7.1 & & \\
\hline Medial phalanx V length & 15.4 & & \\
\hline Medial phalanx $\mathrm{V}$ mid-width & 6.7 & & \\
\hline Distal phalanx V length & 21.4 & & \\
\hline Distal phalanx V width & 8.2 & & \\
\hline
\end{tabular}




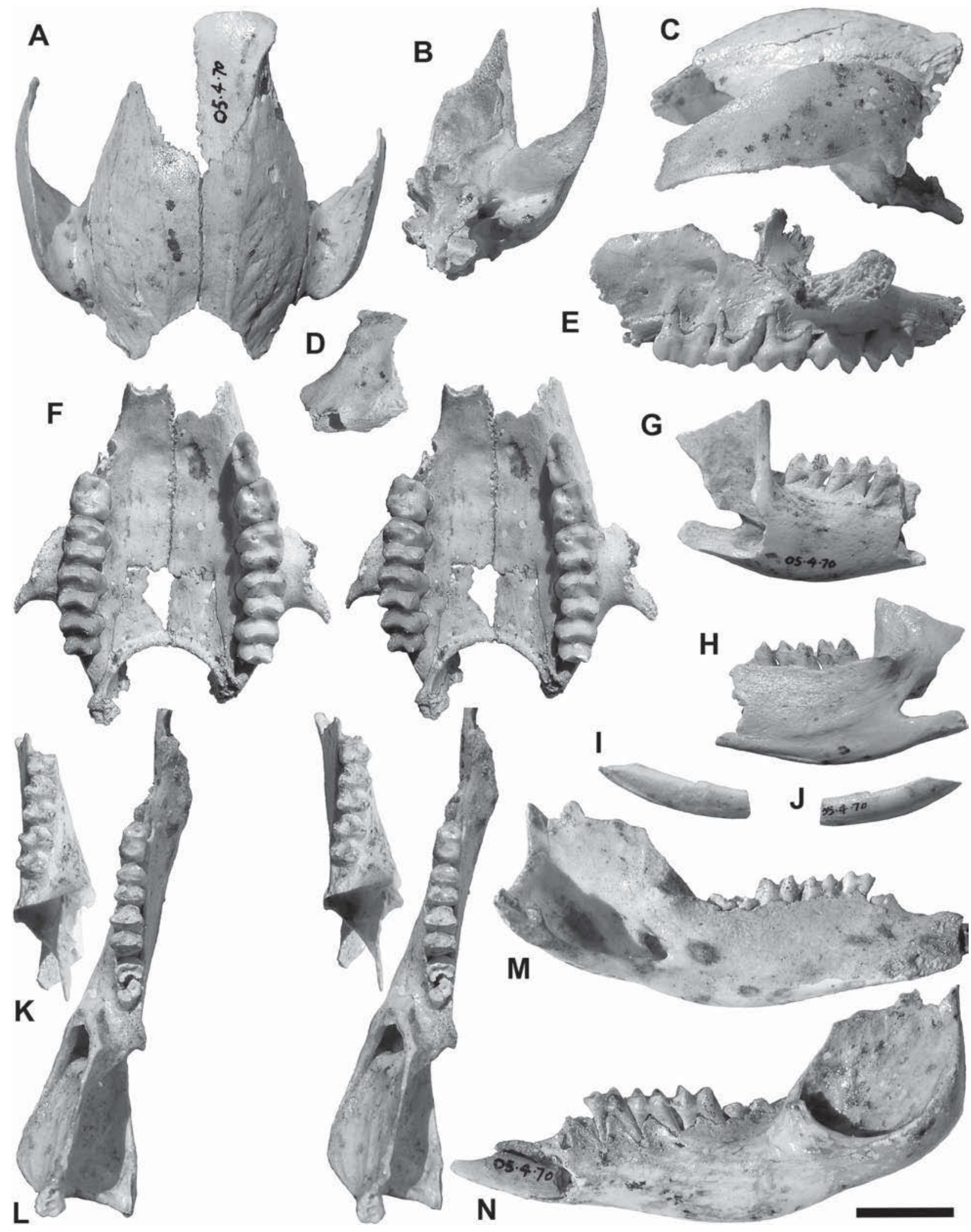

Figure 2 Bohra nullarbora sp. nov. Cranium and dentaries of holotype (WAM 05.4.70). A: neurocranium in dorsal view; B: left squamosal and alisphenoid in ventral view; C: neurocranium in lateral view; D: left premaxilla in lateral view; E: left maxilla in lateral view; F: Stereopair of palate in occlusal view; G: partial right dentary in lateral view; $\mathrm{H}$ : partial right dentary in mesial view; I: right i1 in lingual view; J: right i1 in buccal view; K: stereopair of partial right dentary in occlusal view; L: stereopair of left dentary in occlusal view; M: left dentary in mesial view; N: left dentary in lateral view. Scale bar equals $20 \mathrm{~mm}$. 


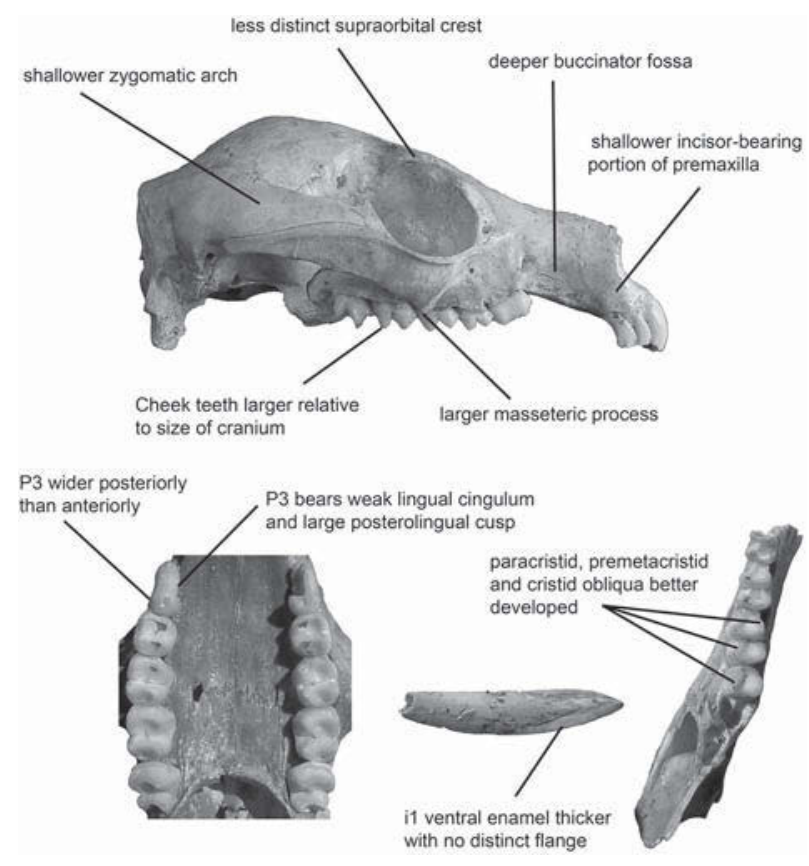

Figure 3 Craniodental features of Bohra illuminata that differentiate it from B. nullarbora sp. nov.

with lower teres major insertion; distal articular surface (especially capitulum) relatively narrow. Ilium relatively broader anteroposteriorly, with medial border more sinuous; marked oval fossa contiguous with rugose muscle scar of $\mathrm{M}$. rectus femoris dorsal to acetabulum. Epipubic very large. Calcaneus larger with partial separation of posterior calcaneal-talar facets, shorter anterior plantar sulcus, better developed plantar tuberosity, wider sustentaculum tali, and lateral talar facet of calcaneus relatively narrow and less tapered mesially. Talus relatively longer with higher lateral trochlear ridge. Metatarsal IV more robust with larger cuboid facet, less medially constricted facet for metatarsal $\mathrm{V}$ and less rounded, less distally oriented sesamoid facet. Metatarsal V more robust.

\section{Etymology}

The species refers to the region of origin, the Nullarbor Plain.

\section{Description}

\section{Cranium}

Incisor-bearing portion of premaxilla short and deep; upright portion essentially vertical. Anterior edge of premaxilla gently curved in lateral view (Figure 2D). Diastema short, straight and deflected anteroventrally relative to cheek tooth row; maxilla contributes to most of diastema length. Central region of diastema not preserved. Most of incisive foramina not preserved, but anterior remnants suggest they were broad, and extended anteriorly to adjacent to midpoint on $\mathrm{I} 3$ alveolus. Most of rostrum not preserved, but lower portion of lateral surface of left maxilla reveals shallow, poorly demarcated posterior half of buccinator fossa (Figure 2E-F). Mesial portions of premaxillae not preserved, but narial aperture apparently near-circular. Masseteric process not preserved on either side of cranium, but enough of maxilla preserved beneath right orbit to indicate process was tiny and positioned adjacent to M2-3 abutment (Figure 2E-F). Infraorbital foramen opens anteriorly; positioned directly above posterior root of P3. Lacrimals, jugals, nasals and anterior half of frontals not preserved.

Posterior part of frontal slightly concave on dorsal surface and bears distinct, but incomplete, supraorbital crest above posterior portion of orbit (Figure 2A). Distinct sulcus formed beneath supraorbital crest. Palatine bones well developed; palate non-fenestrate except for two small foramina on maxilla-palatine suture, adjacent to M3 protoloph (Figure 2F). Palate terminates posteriorly adjacent to M4 metaloph. Temporal (parietal) crests weakly developed, confluent anteriorly with supraorbital crests (Figure 2A). Interparietal, occiput and basicranium not preserved, except for left alisphenoid, which is markedly extended posteriorly, evidently to paroccipital process (Figure 2B). Dorsal surface of neurocranium domed (Figure 2C). Zygomatic arch moderately deep; jugal not preserved, but shallow jugal fossa on squamosal reflects rather wide ectoglenoid process (Figure 2B). Zygomatic process of squamosal arises well anterior of occiput. Large, ventrally projected postglenoid process forms posterior border of glenoid fossa (Figure 2C). Ectotympanic missing. Subsquamosal foramen large; positioned adjacent to posterior extremity of zygomatic process of squamosal.

\section{Upper Dentition}

P3 crown oriented anterodorsally at $20^{\circ}$ to palatal plane (Figure 2E). P3 longer than all molars. Crown is wider anteriorly than posteriorly due to rounded eminence on buccal side, absence of posterobuccal accessory cusp, and small, low nature of posterolingual cusp (Figure 2F). Main crest straight and oriented along longitudinal axis of tooth. Posterior basin very poorly demarcated. Very low, rounded lingual cingulum extends smoothly from immediately anterior to posterolingual cusp to anterior end of crown. Buccal cingulum absent. Main crest composed of four connected cuspules, with anteriormost and posteriormost more distinct (Figure 2E). Two very weak vertical ridgelets lie between slightly larger eminences corresponding to anteriormost and posteriormost cuspules on buccal surface of tooth.

Upper molars low crowned. M1 very worn, dentine of protoloph, metaloph and postprotocrista 
breached and continuous; M2 worn, dentine of protoloph and metaloph crests breached; M3 crests moderately worn, dentine breached only at protocone apex; M4 crests slightly worn. Protoloph narrow than metaloph on M1, but wider on M2-4, becoming progressively more so from M2 to M4 (Figure 2F). M1-2 shorter relative to width than M34. Loph faces smooth with no enamel crenulations or secondary cristae, except for extremely slight eminence buccal to posterior end of postprotocrista on M1, which represents cusp C portion of stylar crest. Preparacrista low, but distinct; maintains connection with paracone apex on all molars. Postprotocrista barely evident; manifested as very low, rounded eminence on posterior face of protoloph, and only marginally more distinct in interloph valley (Figure 2F). Postparacrista low and oriented anteroposteriorly. Premetacrista very weakly developed. Postmetaconulecrista very low near metaconule apex, and thickens only marginally posterodorsally as it extends across posterior face of metaloph. Postmetacrista very low and weakly developed.

\section{Dentary}

Ramus stout; deep relative to width, particularly beneath posterior molars. Depth below m3 interlophid valley $19.8 \mathrm{~mm}$; width $9.3 \mathrm{~mm}$. Dentary depth gradually increases posteriorly from symphyseal region to beneath $\mathrm{m} 4$, where digastric eminence is deepest (Figure 2M,N). Diastema region broken, but clearly short and quite deep. Symphyseal plate rugose; restricted to ventral half of anteromesial aspect of dentary. Genial pit well developed. Symphysis extends posteriorly to beneath anterior root of p3 (Figure 2M). Anterior mental foramen large; positioned below anterior extremity of p3. Buccinator sulcus straight and moderately deep along entire length, extending from immediately behind anterior mental foramen to beneath $\mathrm{m} 2$ hypolophid. Digastric sulcus distinct, extending from beneath anterior end of medial pterygoid fossa to anteriorly to beneath $\mathrm{m} 3$ protolophid (Figure 2H,M). Anterior root of vertical ascending ramus adjacent to portion of postalveolar shelf immediately posterior to $\mathrm{m} 4$ hypolophid (Figure 2G,H). Postalveolar process distinct and posteromesially projected. Angular process (medial pterygoid fossa) slightly inflated posteriorly; tip of angular process distinct and posteromesially projected. Masseteric fossa quite deep, largely due to laterally expanded posteroventral border. Ventral border of masseteric fossa at level of posterior end of buccinator sulcus (Figure 2N). Anterior insertion area for second layer of masseter muscle distinct, but not especially large. Masseteric foramen moderately large (Figure 2L), anteroventrally oriented and leads into masseteric canal, which extends to beneath $\mathrm{m} 3$. Inferior mandibular foramen egg shaped, opening largely posteriorly. Articular and coronoid processes not preserved.

\section{Lower Dentition}

Stout i1 upturned $20^{\circ}$ relative to longitudinal axis of ramus (Figure 2N). Straight occlusal surface lies in same plane as longitudinal axis of ramus, i.e., worn at $20^{\circ}$ relative to axis of i1 (Figure 2I,J). Lingual surface of i1 devoid of enamel. Extension of buccal enamel forms quite thick dorsal flange. Posterior end of ventral enamel flange very thin (Figure 2I).

Lower molars low crowned; m1-2 very worn, dentine of protoloph and metaloph crests breached; $\mathrm{m} 3$ crests moderately worn, dentine breached only at protoconid apex; $\mathrm{m} 4$ crests slightly worn. Protolophid and hypolophid crests only slightly curved posteriorly and close to parallel; oriented perpendicular to molar midline (Figure 2K,L). Lophid faces smooth; anterior faces gently sloping due to marked anteroposterior thickness of lophids, particularly toward base. Posterior portion of paracristid low and rounded; point at which paracristid inflects lies in midline of tooth at anterior extremity of crown. Anterior portion of paracristid thickened; terminates short of anterolingual corner creating distinct anterolingual notch (Figure 2K,L). Precingulid small, low and oriented at $45^{\circ}$ to tooth midline. Low broad parametacristid most distinct on $\mathrm{m} 4$; extends into center of trigonid basin, terminating against middle of paracristid (Figure 2K). Cristid obliqua very low, barely more than a low eminence. Preentocristid not evident.

\section{Vertebrae}

Atlas (C1) large and robust laterally, marked posteriorly by semicircular depressions on either side of small, anterior mid-dorsal crest. Halves of atlas unfused mid-ventrally. Lateral masses of atlas possess articular facets anteriorly and posteriorly. Anterior facets medially directed and deeply concave with marked dorsal lip corresponding to occipital condyles. Posterior concave facets very shallow. Transverse processes are broad and extend slightly ventrally. Processes constricted at base, then expand distally with a semicircular margin. Epineural canal positioned at base of transverse process, posterior to margin of occipital fossa.

Axis (C2) with neural arch relatively square in lateral view, slightly convex anteriorly and thickened along dorsal border. Neural canal dorso-ventrally compressed resulting in oval section. Broad, convex prezygapophyses cover anterior aspect of centrum on either side of odontoid process. Process short (though abraded) and circular in section. Slender pleurapophyses ventrally directed. Postzygapophyses very short, 

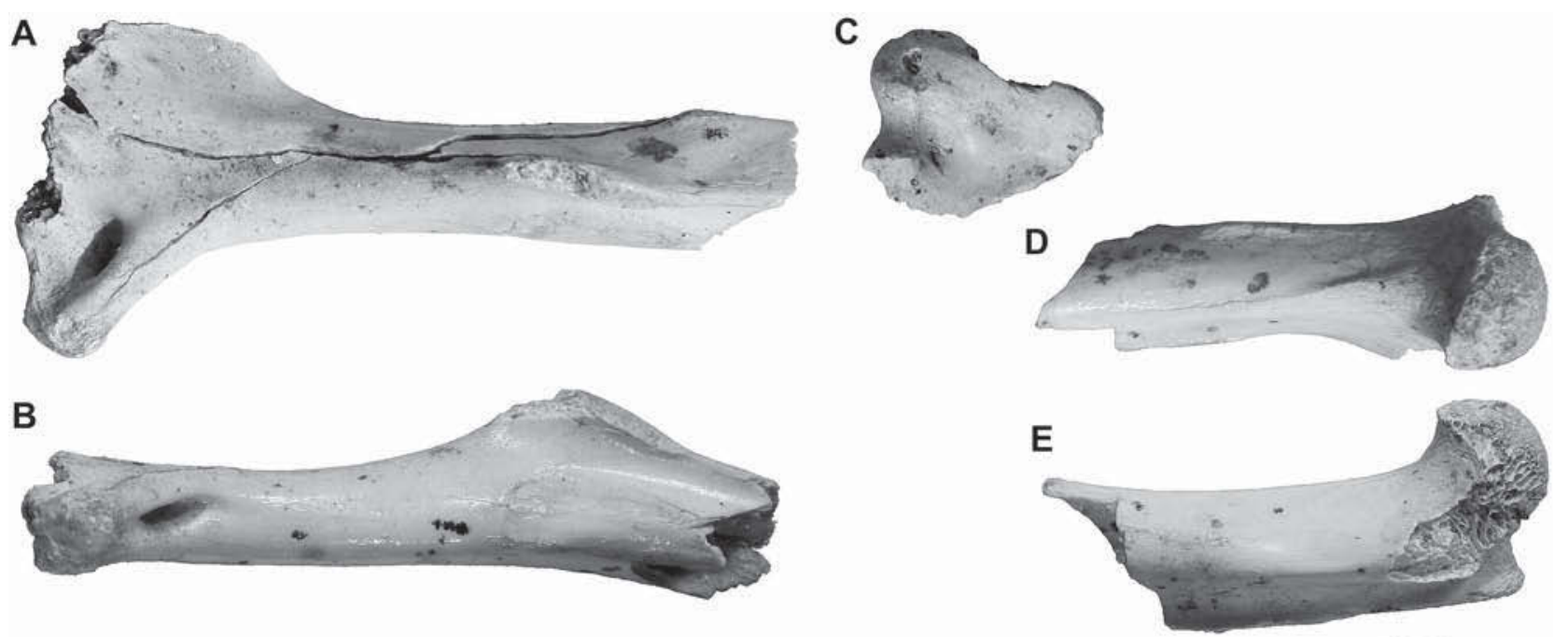

$\mathbf{F}$
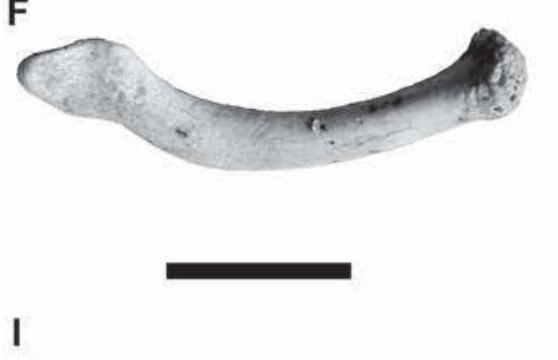

G

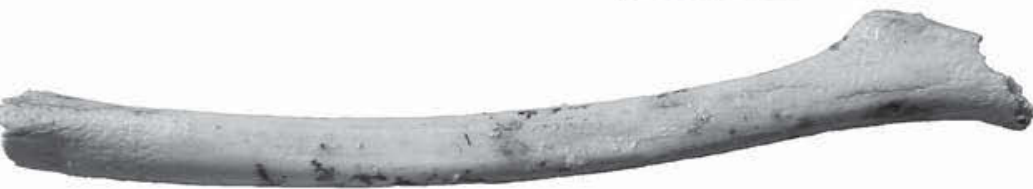

$\mathrm{H}$
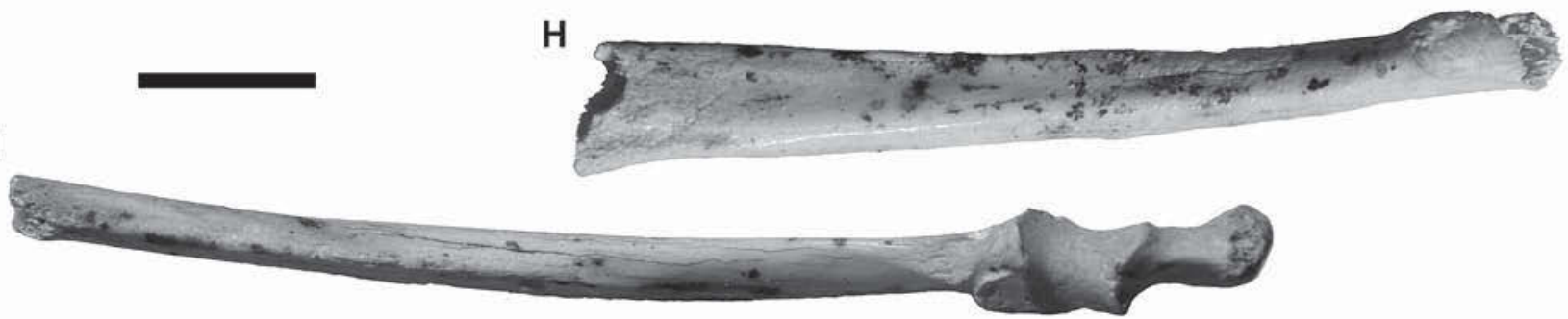

Figure 4 Bohra nullarbora sp. nov. Forelimb elements of holotype (WAM 05.4.70). A: incomplete right humerus in anterior view; B: right humerus in medial view; C: distal end of left humerus in anterior view; D: proximal end of left humerus in medial view; E: left humerus in anterior view; F: left clavicle in anterior view; G: left radius in ventral view; H: left radius in medial view; I: left ulna in dorsal view. Scale bar equals $20 \mathrm{~mm}$.

facets posteroventrally directed. Centra with small mid-ventral keel, and two small protuberant ventrolateral muscle/ligament insertion scars. Centra of fragmentary cervical vertebrae 3-5 rectangular in section. Low, broad neural canal; stout neural arches anteriorly inclined. Anterior zygapophyses large rounded articular surfaces; posterior zygapophyses very short and broad. Pleurapophyses long, tapered and posteriorly inflected. Small parapophyses arise from anterior base of pleurapophyses.

Anterior thoracic vertebrae (T) with small centra, semicircular in cross-section, becoming deeper and longer along thoracic series. Neural spine of $\mathrm{T} 1$ robust and slightly posteriorly directed. Neural spines of T5-6 at approximately $50^{\circ}$ to horizontal; neural spines of T10-12 relatively low, and almost vertical. Neural canal sub-triangular in T1; becomes circular through mid-post thoracic region. Transverse processes moderately long and rounded with lateral costal demifacets.
Single fragment of lumbar vertebrae badly degraded and uninformative.

Mid-caudal vertebrae large and robust. Long centra bear modestly developed zygapophyses. Neural canal present as narrow, mid-dorsal groove. Ventral haemal canal shallow; relatively broader than neural canal. Transverse diapophysial projections moderately wide and robust.

\section{Clavicle}

Robust, flattened anteroposteriorly. The sternal end is expanded and globular, with an oval articular surface and non-articular depression (Figure 4F). The shaft constricts, becomes compressed, then broadens at its acromial end. The bone is bent, arcing forwards in its lateral third. Obvious line of muscle attachment for pectoral muscles along anterior edge. Acromial end flattened, the concave ventral articular facet elongate and bounded by rugose ligament scars. Distinct dorso-lateral projection from acromial end. 

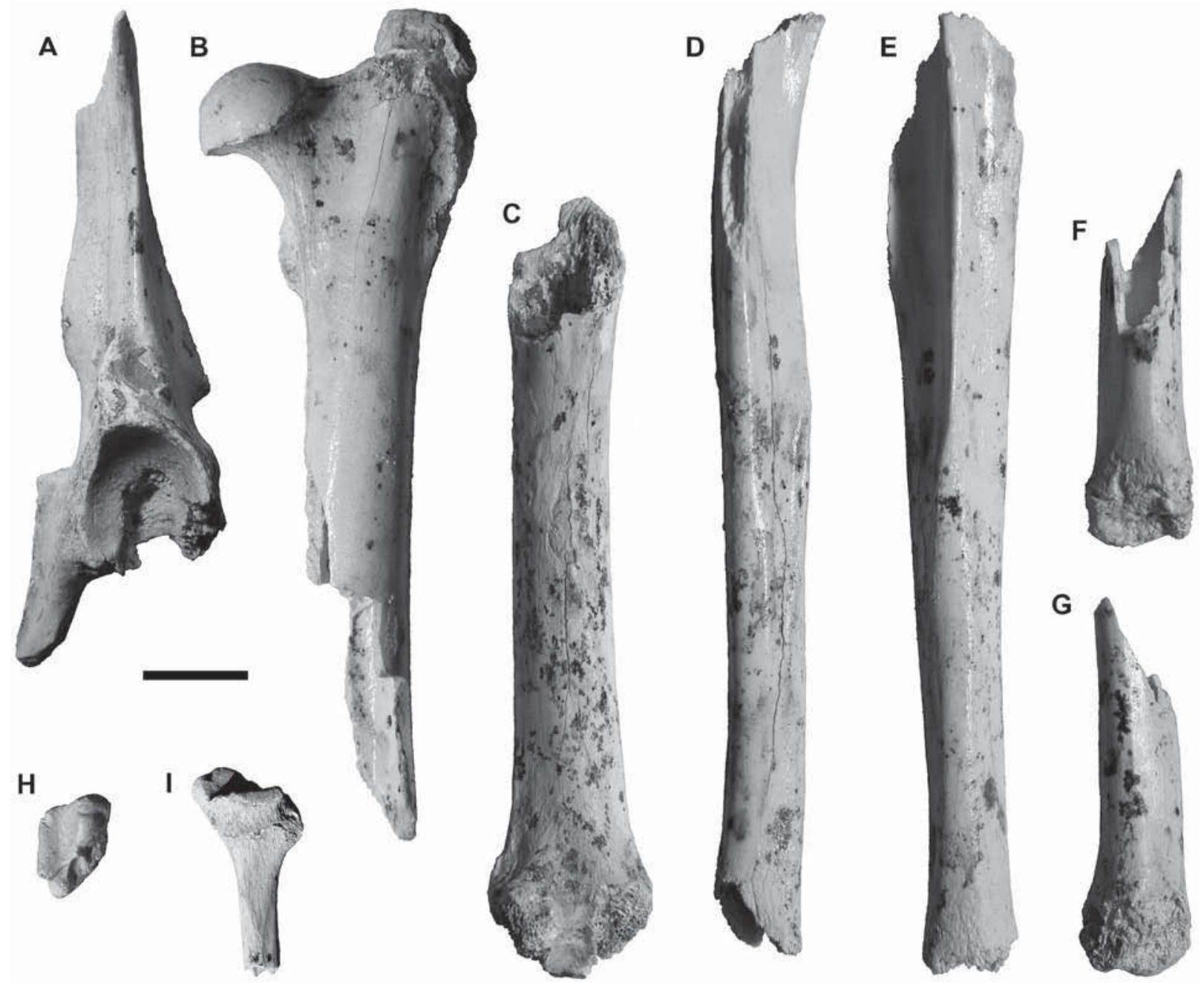

Figure 5 Bohra nullarbora sp. nov. Hindlimb elements of holotype (WAM 05.4.70). A: left innominate in lateral view; B: partial left femur in anterior view; C: partial right femur in anterior view; D: right tibia in anterior view; E: right tibia in lateral view; F: distal end of left tibia in anterior view; G: left tibia in posterior view; H: distal end of left fibula in medial view; I: left fibula in distal view. Scale bar equals $20 \mathrm{~mm}$.

\section{Humerus}

Robust humerus (Figure 4A-E) with massive pectoral crest, strong deltoid ridge, and deep bicipital groove. Accessory spino-deltoid crest as obvious process on proximal third of lateral surface of shaft; oblique line weakly developed. Distinct rugose insertion for humeral adductor muscles (teres major and/or latissimus dorsi muscle) evident medially with thickening of the shaft and obvious scars on proximal half of medial shaft. Distal surface of humerus transversely broad; capitulum large; lateral supracondylar ridge long and moderately developed. Medial epicondyle robust and transversely broad. Bar over medial condylar fossa particularly robust. Posterior olecranon fossa moderately deep.

\section{Radius}

Very robust radius (Figure $4 \mathrm{G}, \mathrm{H}$ ) with massive bulbous insertion for biceps brachii muscle. Shaft expands anteroposteriorly from below this muscular insertion and is compressed mediolaterally in distal half. Interosseous ridge strongly developed. Distinct muscle attachment sites for strong rotator muscles laterally and digital flexor muscles disto-medially. Proximal and distal epiphyses missing.

Ulna

Long ulna with transversely compressed shaft, anteroposteriorly expanded proximally and distinctly tapered distally (Figure 4I). Outline of ulna very slightly sinuous in anterior view, arching laterally at shaft mid-region and curving medially towards the distal end. Shaft curved when viewed laterally, with deep ventral inflection in posterior third. Olecranon robustly developed. Trochlear (semilunar) notch and coronoid process rather narrow transversely, and wide longitudinally. Radial facet very flat, deep longitudinally; roughly round in shape and buttressed out slightly from 

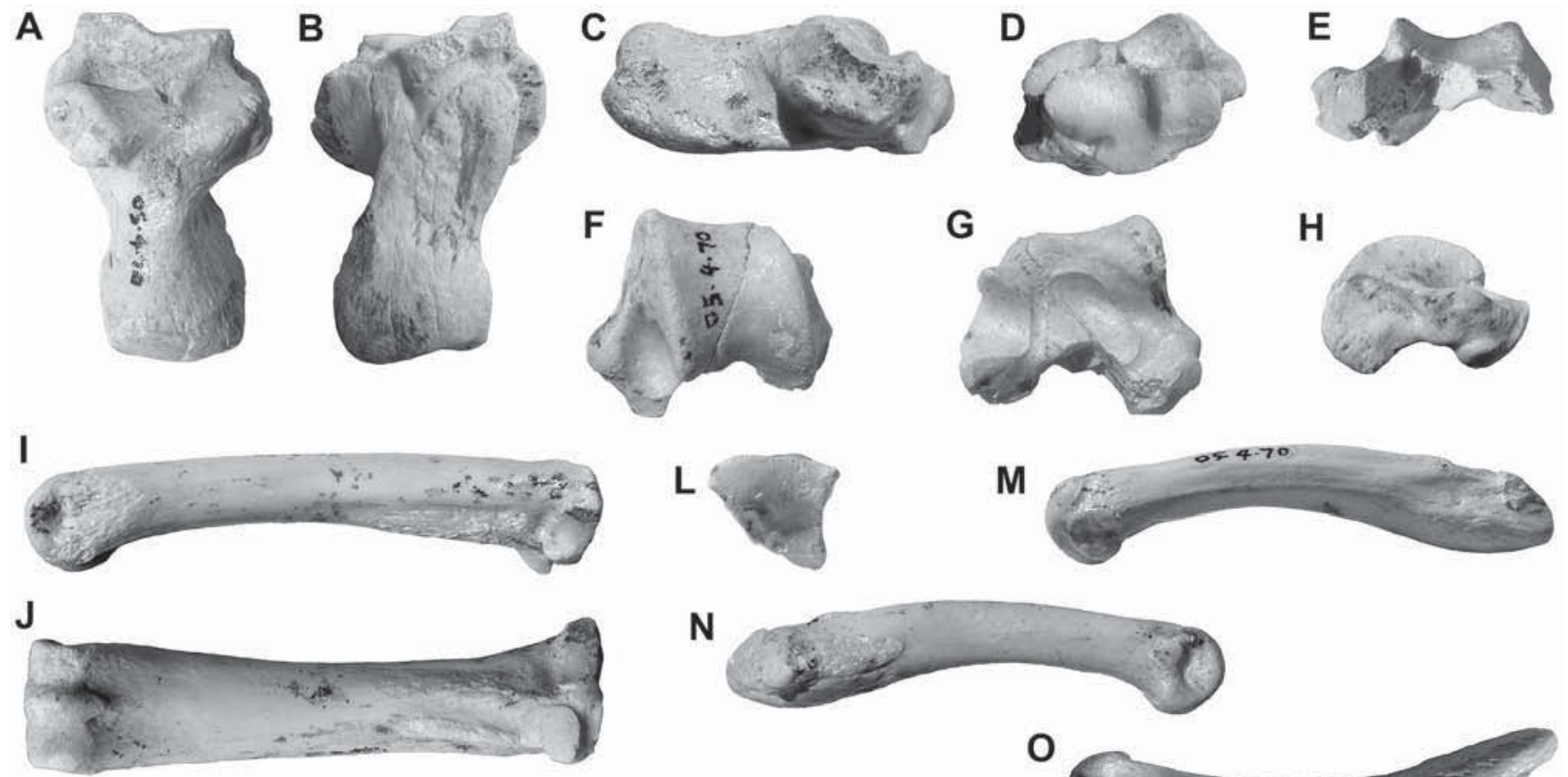

$\mathbf{N}$
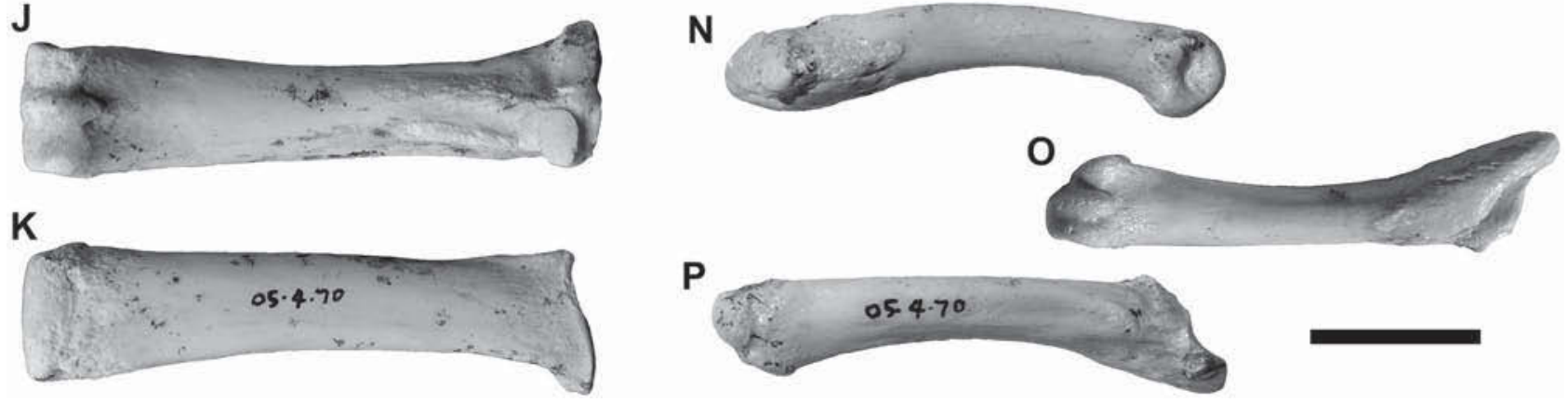

Figure 6 Bohra nullarbora sp. nov. Pedal elements of holotype (WAM 05.4.70). A: left calcaneus in dorsal view; B: calcaneus in plantar view; C: calcaneus in medial view; D: calcaneus in anterior view; E: left talus in anterior view; F: talus in dorsal view; G: talus in ventral view; H: talus in medial view; I: left metatarsal IV in lateral view; J: metatarsal IV in plantar view; K: metatarsal IV in dorsal view; L: metatarsal IV in posterior view; M: left metatarsal V in lateral view; $\mathrm{N}$ : metatarsal V in medial view; O: metatarsal V in plantar view; P: metatarsal V in dorsal view; Q: phalanges of digit IV. Scale bar equals $20 \mathrm{~mm}$.

shaft. Obvious muscular attachment for digital flexor with deep proximo-medial sulcus and rugose scar from M. brachialis anterior to the trochlear notch. Interosseous border bear strong ridge in distal half. Styloid process well-formed with hemispherical articular surface.

\section{Carpals}

Hamatum large; elongate in anterior view, with mesiodistal expansion for metacarpal IV articulation. Facet for metacarpal V concave. Posterior surface of hamatum comprises bulbous medial projection and elongate posterolateral process separated by oblique fossa. Posterolateral projection large, rounded and at its tip ventrally expanded. Medial projection dorsally convex, oval in outline, and obliquely oriented. Laterally, a short, irregular shelf present upon which triquetrum sits. Scaphoid large, transversely elongate, and proximodistally compressed. Proximal surface convex for articulation with distal radius. Medially expanded with round ended projection. Mesial surface with large, shallow concave facets for hamatum and capitulum; small distal facets for trapezoid and trapezium.

\section{Metacarpals and Phalanges}

Five metacarpals short and robust. Metacarpal I is particularly stout; remainder increase in relative shaft thickness from metacarpal II through V. Metacarpal III is longest. Asymmetrical proximal ends bear distinct lateral expansions and shallow, concave articular facets. Palmar surface of metacarpal shafts concave in profile; dorsal surface straight. Proximal phalanges long and thin compared to middle series. Distal carpal phalanges long and curved, proportionately more transversely compressed and gracile than distal tarsal phalanges.

\section{Innominate}

Partial left innominate consists of acetabulum, and fused bases of ilium, and pubis; separate fragments of both right and left ischial bases (Figure 5A). Ilium subtriangular in section; anterior ridge swollen at sacroiliac facet but 
diminishes in height rapidly as it continues forwards. The rugose muscle scar (M. rectus femoris) situated immediately dorsal to acetabulum is irregular with both an elongate raised portion and a (an unusual) dorsal deep oval fossa. Acetabulum large and deep with deep acetabular fossa; dorsal ischiocotylar portion of articular facet large; pubocotylar articular (ventral) portion reduced. Base of pubis deep and flattened; iliopectineal tuberosity apparently moderately well-developed. Base of ischium transversely flattened.

\section{Epipubic}

Large, long, dorsoventrally flattened epipubic bones. Proximally, epipubic is ventrally thickened for articular surface. Ascending body of epipubic bone slightly laterally convex, constricting towards distal tip.

\section{Femur}

Head not quite hemispherical in shape with fovea located slightly posteriorly. Greater tuberosity large (Figure 5B). Lesser tuberosity obvious with a distally extended ridge (Figure 5B). Diaphysis slightly antero-posteriorly compressed. Mid-posterior surface of shaft marked by obvious muscle scar (Figure 5C). Distal epiphyseal condyles badly abraded.

\section{Tibia}

Tibia (Figure 5D-G) with longitudinal axis of diaphysis straight anteroposteriorly and sinuous laterally in proximal third. Strongly developed anterior tibial crest bears laterally inflected anterior ridge, which ends abruptly approximately one-quarter along length of diaphysis. Fibular articulation marked on distal half of lateral surface of shaft. Proximal end of diaphysis expanded for triangular proximal epiphysis.

\section{Fibula}

Proximal epiphysis (Figure 5H,I) with large eminence from lateral-posterior region of proximal surface for articulation with femur epicondyle. Medially, a proximally directed articular shelf and elongate medial facet for tibial articulation. Anterior knob for origin of M. peroneus longus and posterior pit for tendon of M. popliteus are distinct. Proximal diaphysis transversely compressed (Figure 5I).

\section{Calcaneus}

Tuber calcanei very broad and medially expanded (Figure 6A,B); rounded trapezium shape in posterior view. Deep sulcus crosses posterior aspect of tuberosity ventrolaterally from medial border. Stout shaft subtriangular in cross-section. Dorsomedial crest flattened and expands posteriorly. Broad plantar surface roughened and slightly concave; expanded posteriorly onto epiphysis (Figure 6B). Plantar surface interrupted anteriorly by broad sulcus that crosses obliquely from flexor sulcus on sustentaculum tali (Figure 6B). Anterior margin of plantar surface marked by distinct (but slightly abraded) plantar tuberosity on boundary of ventromedial facet of calcaneal-cuboid articulation. Sustentaculum tali broad transversely (Figure 6B); flexor sulcus relatively shallow and almost level with plantar surface anteriorly (Figure 6C). From medial aspect, sustentaculum tali is quite deep dorsoventrally, almost horizontal, and only slightly convex ventrally.

Articular facets for talus expansive (Figure 6A). Ovoid medial facet is contiguous with sustentacular facet mesially. Lateral talar facet high, rounded and convex; expands laterally. Lateral and medial facets separated by distinct groove, although posteriorly lateral facet extends slightly medially (Figure 6A). Anteromedial facet for articulation with talar head indistinct. Subtriangular posterolateral aspect of lateral calcaneal-talar facet expanded for articulation with fibula (Figure 6D). Irregular concave area immediately anterior to fibular contact represents attachment of fibular ligaments. Large, broad subarticular ridge extends anteroventrally from fibular contact. Dorsomedial facet for cuboid transversely broad, ovoid and slightly convex (Figure 6D). Dorsolateral facet smaller and squarer in outline. Step between two facets smoothed and obliquely oriented when viewed dorsally. Narrow ventromedian facet contiguous with dorsolateral facet, and separated mesially from lateral half of dorsomedial facet by steep notch (Figure 6D).

\section{Talus (= astragalus)}

Transversely very broad, with marked medial expansion of medial malleolus and talar head (Figure 6E-H). Sub-parallel trochlear crests high, rounded and widely separated; medial crest positioned slightly more posteriorly than lateral crest (Figure 6F). Medial crest steeper and higher than lateral crest. Broad, concave trochlear sulcus slightly more steeply inclined medially (Figure 6 E). Greatly expanded medial malleolus separated from body of talus by large, circular malleolar fossa (Figure 6F). Medially displaced talar head obliquely oriented and expanded ventromedially (Figure 6G,H). Distolateral process broad dorsoventrally. Two deeply concave facets for articulation with calcaneus dominate ventral surface of talus (Figure 6G). Facets separated by distinct groove. Posteromedially, medial facet overhung by large posteroventral process. Anteromedially, medial facet separated from articular surface of talar 
head by wide groove across the talar neck (Figure $6 \mathrm{G})$.

\section{Navicular}

Robust bone, transversely compressed. Proximally concave for head of talus. Lateral surface concave for articulation with cuboid; distinct depression for cuboid-navicular ligaments. Distal surface marked by teardrop shaped dorsal facet for entocuneiform and elongate, irregularly shaped medial facet for ectocuneiform separated by distinct but irregularly shaped groove. Plantar surface swollen and medially inflected.

\section{Entocuneiform}

Proximally swollen and distally transversely compressed. Proximal facet shallowly concave and roughly teardrop shaped for corresponding surface of navicular. Medial surface smoothly concave. Lateral surface irregular in form with small dorsal facets, one proximal and one distal, for ectocuneiform and mesocuneiform respectively. Distal surface with shallow ovoid depression for medial aspect of head of metatarsal II.

\section{Metatarsal IV}

Large, dorsoventrally flattened and slightly expanded distally. Shaft slightly concave ventrally; expands gently to meet distal epiphysis when viewed dorsally (Figure 6K). Proximal epiphysis subtriangular in section and expanded dorsolaterally (Figure 6L). Two facets for metatarsal $\mathrm{V}$ continuous and greatly expanded transversely, forming elongate, ovoid, slightly concave articular surface (Figure 6I,J). Very slight medial constriction separates facets. Plantar tuberosity bears large flat, ovoid facet for plantar sesamoid (Figure 6J). Shallow, concave sulcus for articulation of metatarsals II-III present proximomedially. Proximal third of plantar surface of metatarsal IV marked by two roughened ridges extending distally from either side of plantar tuberosity (Figure 6J). Steep groove for interosseous connections present laterally. Distal epiphysis broad and convex. Medial and lateral faces marked by deep, circular fossae (Figure 6I,J). Medial and lateral plantar crests roughly equal in height. Narrow, high, central crest slightly displaced toward lateral side (Figure 6J).

\section{Metatarsal $V$}

Narrow shaft strongly curved laterally (Figure 6P) and markedly dorsally (Figure 6M). Small lateral tuberosity present on dorsal aspect of shaft below articular facets. Proximally, subtriangular facet for lateral tuberosity of cuboid slightly concave along dorsoventral axis. Facet extends posteriorly onto enlarged proximolateral tuberosity (Figure $6 \mathrm{P})$. Tuberosity elongate and rugose on swollen plantar surface (Figure 6O). Groove demarcating border of cuboid facet extends along proximal boundary. Facets for articulation with metatarsal IV combined to make single, enlarged articular area corresponding combined facets of metatarsal IV (Figure 6N). Small ventromedial process positioned just posterior to medial boundary of facets for metatarsal IV. Asymmetrical distal epiphysis greatly reduced on lateral side (Figure 6O,P). Together, enlarged central and medial crests form trochlear articulation for proximal phalanx.

\section{Phalanges of Digits II-III}

Proximal and medial phalanges of digits II or III have been identified. Proximal phalanx elongate and very gracile. Proximal articular surface expanded from shaft and near-circular. Distal articular surface transversely compressed forming deep trochlea. Medial phalanx very small, approximately half the length of the proximal phalanx. Articular surfaces transversely compressed; proximal facet with small medial keel; distal facet with deep trochlear shape.

\section{Phalanges of Digits IV}

Proximal and, in particular, distal articular surfaces compressed dorsoventrally. Proximal articular surface elliptical and shallowly concave. Well-developed ventral tuberosities for plantar sesamoid bones separated by wide V-shaped groove. Distal articular surface hourglass shaped. Medial phalanx approximately two-thirds length of proximal phalanx. Stout diaphysis constricted between expanded articular surfaces. Proximal articular surface dorsoventrally compressed, saddle shaped and deeply concave. Expansive distal articular surface bears crests ventrolaterally oriented on ventral surface. Distal phalanx long, laterally compressed and hooked.

\section{Phalanges of Digits $V$}

Proximal phalanx of digit $\mathrm{V}$ approximately half size of digit IV equivalent. Proximal articular surface slightly ovoid and obliquely aligned, so that articulation with head of metatarsal $\mathrm{V}$ is asymmetrical. Sesamoid tuberosities large, rounded, and separated by small ' $\mathrm{V}$ ' shaped notch. Medial phalanx stout. Proximal articular surface deeply concave.

\section{DISCUSSION}

The description of Bohra nullarbora brings the total number of described species in this genus to four. Features of the limbs, and in particular the hind foot, clearly indicate that the three species represented by postcranial remains (B. nullarbora, $B$. illuminata, B. paulae) were well adapted to living in trees. Differences between the species probably reflect slight variations in climbing styles and 
abilities, and precise ecological niches occupied, as they do in modern species of Dendrolagus (Flannery et al. 1996; Harvey 2006; Warburton and Prideaux in press). On balance, the realisation that two tree-kangaroos were inhabitants, around half-amillion years ago, of the region we now call the 'Treeless' Plain is about as good an indication as one can get of how incompletely we understand even the relatively recent historical zoogeography of the Australian biota. In particular, it says two very interesting things. First, despite having a remarkably similar climate to today, the Nullarbor Plain was once much better vegetated, a shift that may have been wrought by increasing frequency and/or intensity of bushfires (Prideaux et al. 2007; Warburton and Prideaux in press). Second, treekangaroos might now be denizens of the wetter forests of northeastern Australia and New Guinea, but this was not always so. Indeed, one of the key advances facilitated by the relatively complete preservation of the fossil skeletons retrieved from the Thylacoleo Caves is the ongoing identification of incomplete tree-kangaroo specimens (e.g. partial jaws, isolated teeth and foot bones) from other late Cenozoic localities in Australia and New Guinea. A picture is just beginning to emerge of a diverse group of arboreal folivores adapted to a wide range of wooded habitats from rainforest (e.g. Hocknull $2005 a, b)$ to open woodland (e.g. Prideaux et al. 2007), occupying niches perhaps most comparable with larger lemurs or monkeys elsewhere.

\section{ACKNOWLEDGEMENTS}

We thank the following individuals and institutions for the loan of or access to comparative specimens: Norah Cooper, Western Australian Museum; Robert Jones, Australian Museum; Scott Hocknull, Steve Van Dyck, Heather Janetski and Kristen Spring, Queensland Museum; Robert Palmer, Australian National Wildlife Collection; David Stemmer, South Australian Museum; Robert Voss, American Museum of Natural History. Clay Bryce, Paul Devine, Lindsay Hatcher, John Long, Mark Norton and Eve Taylor provided field assistance. We are grateful to Grant Gully for taking the photographs in figures 3-4. This study was supported by the Rio Tinto WA Future Fund and an anonymous donation to the Western Australian Museum Foundation. Bernard Cooke, Tim Flannery and an anonymous reviewer are thanked for their comments.

\section{REFERENCES}

Dawson, L. (2004). A new Pliocene tree kangaroo species (Marsupialia, Macropodinae) from the Chinchilla Local Fauna, southeastern Queensland. Alcheringa 28: 267-273.

Flannery, T.F. (1989). Phylogeny of the Macropodoidea; a study in convergence. pp1-46 In: Grigg, G.C., Jarman, P.J. and Hume, I.D. (eds), Kangaroos, Wallabies and
Rat-kangaroos: Surrey Beatty \& Sons: Chipping Norton, NSW.

Flannery, T.F. (1990). Mammals of New Guinea. Robert Brown and Associates: Brisbane, QLD.

Flannery, T.F., Martin, R. and Szalay, A. (1996). Tree-kangaroos: a Curious Natural History. Reed Books: Melbourne, VIC.

Flannery, T.F. and Szalay, F.S. (1982). Bohra paulae: a new giant fossil tree kangaroo (Marsupialia: Macropodidae) from New South Wales, Australia. Australian Mammalogy 5: 83-94.

Flower, W.H. (1867). On the development and succession of teeth in the Marsupiala. Philosophical Transactions of the Royal Society of London B 157: 631-641.

Gray, J.E. (1821). On the natural arrangement of vertebrose animals. London Medical Repository 15: 296-310.

Harvey, K. (2006). A Morpho-functional Assessment of the Forelimb in the Macropodinae, with Implications for the Paleobiology of the Pleistocene Tree Kangaroo, Bohra illuminata: 1-128, unpublished B.Sc.(Hons) thesis, School of Animal Biology, University of Western Australia: Perth, WA.

Hocknull, S.A. (2005a). Additional specimens of Bohra (Marsupialia: Macropodidae) from the Pliocene of Queensland. Memoirs of the Queensland Museum 51: 26.

Hocknull, S.A. (2005b). Ecological succession during the late Cainozoic of central eastern Queensland: extinction of a diverse rainforest community. Memoirs of the Queensland Museum 51: 39-122.

Hocknull, S.J., Zhao, J.-x., Feng, Y.-x. and Webb, G.E. (2007). Responses of Quaternary rainforest vertebrates to climate change in Australia. Earth and Planetary Science Letters 264: 317-331.

Luckett, W.P. (1993). An ontogenetic assessment of dental homologies in therian mammals pp182-204. In: Szalay, F.S., Novacek, M.J. and McKenna, M.C. (eds), Mammal phylogeny, volume 1, Mesozoic differentiation, multituberculates, monotremes, early therians, and marsupials: Springer-Verlag: New York, NY, USA.

Owen, R. (1866). On the Anatomy of Vertebrates. Volume II. Longmans, Green: London, UK.

Owen, R. (1876). On the osteology of the Marsupialia. Part V. Fam. Poephaga, Genus Macropus. Transactions of the Zoological Society of London 9: 417-446.

Murray, P.F. (1995). The postcranial skeleton of the Miocene kangaroo, Hadronomas puckridgi Woodburne (Marsupialia, Macropodidae). Alcheringa 19: 119-170.

Nomina Anatomica Veterinaria. (2005). International Committee on Veterinary Gross Anatomical Nomenclature, 5th ed. http://www.wava-amav.org/ Downloads/nav_2005.pdf.

Prideaux, G.J., Long, J.A., Ayliffe, L.K., Hellstrom, J.C., Pillans, B., Boles, W.E., Hutchinson, M.N., Roberts, R.G., Cupper, M.L., Arnold, L.J., Devine, P.D. and Warburton, N.M. (2007). An arid-adapted middle Pleistocene vertebrate fauna from south-central Australia. Nature 445: 422-425.

Prideaux, G.J. and Warburton, N.M. (2008). A new Pleistocene tree-kangaroo (Diprotodontia: Macropodidae) from the Nullarbor Plain of south-central Australia. Journal of Vertebrate Paleontology 28: 463-478.

Prideaux, G.J. (2004). Systematics and evolution of the sthenurine kangaroos. University of California Publications 
in Geological Sciences 146: i-xvii, 1-623.

Strahan, R. (ed.) (1995). Mammals of Australia. Reed Books: Sydney, NSW.

Warburton, N.M. and Prideaux, G.J. (in press). Functional pedal morphology of the extinct tree-kangaroo Bohra (Diprotodontia: Macropodidae). In: Coulson, G.C. and Eldridge, M.D.B. (eds), Macropods: the biology of kangaroos, wallabies and rat-kangaroos, Surrey Beatty \& Sons: Sydney, NSW.
Weisbecker, V. and Sánchez-Villagra, M.R. (2006). Carpal evolution in diprotodontian marsupials. Zoological Journal of the Linnean Society 146: 369-384.

Wells, R.T. and Tedford. R.H. (1995). Sthenurus (Macropodidae: Marsupialia) from the Pleistocene of Lake Callabonna, South Australia. Bulletin of the American Museum of Natural History 225: 1-111.

Manuscript received 16 May 2008; accepted 9 September 2008. 